\title{
Are Loyalty Programmes Shams? A Study Assessing How Loyalty Programmes can Create Loyalty to the Company Rather than to the Program: An Abstract
}

\author{
Virginie Bruneau and Yuping Liu-Thompkins
}

\begin{abstract}
Many researchers have studied LPs extensively, but their effectiveness remains debatable. Some researchers found positive effects (Keh and Lee 2006), while others have not found any effects of LPs (Sharp and Sharp 1997). Shugan (2005) considers them as shams because they produce liabilities (e.g. promises of future rewards or deferred rebates) rather than assets. They can foster customers' short-term loyalty to the programme instead of developing long-term company loyalty. The objective of this research is to better understand how LPs can produce assets by creating long-term relationships instead of making customers only loyal to the programme and provide liabilities to the company. Based on a dataset matching behavioural and attitudinal data, this research proposes that some behavioural patterns, based on LP members' speed of earning loyalty points and redemption rate, will have an impact on the gap between programme loyalty and company loyalty. While a high speed of earning (combined with low redemption) or a high redemption rate (combined with a low speed of earning) will reduce this gap, a high speed of earning combined with a high redemption rate will increase this gap. Our study contributes to both marketing research and practice in two different ways. First, we investigate the gap between LP loyalty and company loyalty by considering them together as an outcome variable. Previous research has mainly investigated both loyalties separately by investigating what their antecedents are and how LP loyalty affects company loyalty. Second, despite the fact that attitudes and behaviours are closely linked (Fishbein and Ajzen 1975), few research have studied the effects of behaviours on attitudes in an LP context. The present research tries to fill in this gap by exploring the relationship between the LP, customers' attitudes and behaviours.
\end{abstract}

References Available Upon Request

\author{
V. Bruneau $(\bowtie)$ \\ Université Catholique de Louvain, Louvain-la-Neuve, Belgium \\ e-mail: virginie.bruneau@uclouvain.be \\ Y. Liu-Thompkins \\ Old Dominion University, Norfolk, VA, USA \\ e-mail: yxxliu@odu.edu
}

